\title{
Modulation of the Catalytic Activity of Porphyrins by Lipid- and Surfactant-Containing Nanostructures
}

\author{
Iseli L. Nantes, ${ }^{*, a}$ Nelson Durán, ${ }^{a, b}$ Sandra M. S. Pinto, ${ }^{a}$ Fabiana B. da Silva, ${ }^{a}$ \\ Juliana S. de Souza, ${ }^{a}$ Noemia Isoda, ${ }^{a}$ Roberto A. S. Luz, ${ }^{a}$ Tiara G. de Oliveira ${ }^{a}$ and \\ Vinícius G. Fernandes ${ }^{a}$ \\ ${ }^{a}$ Centro de Ciências Naturais e Humanas, Universidade Federal do ABC, Rua Santa Adélia, 166, \\ Bairro Bangu, 09210-170 Santo André-SP, Brazil \\ ${ }^{b}$ Instituto de Química, Universidade Estadual de Campinas, \\ CP 6154, 13083-970 Campinas-SP, Brazil
}

\begin{abstract}
Fatores estruturais que modulam a atividade das porfirinas englobam os ligantes equatoriais, o metal central e o número e estrutura dos seus ligantes axiais. A esses fatores se associam o microambiente fornecido por apoproteínas, solventes e membranas. Porfirinas são bastante utilizadas para a construção de estruturas supramoleculares com diferentes aplicações. A modulação da atividade das porfirinas tem sido freqüentemente obtida pela imitação da natureza, ou seja, fornecimento de diferentes microambientes. A associação das porfirinas a nanoestruturas lipídicas pode mudar a atividade destes compostos de tal forma a mimetizar diferentes enzimas como a SOD, citocromo $\mathrm{P} 450$, peroxidases e outros. As formas reativas das porfirinas são estados de alta valência: metal-oxo- $\pi$ cátion e metal-oxo produzidos pela reação com peróxidos e perácidos. A modulação da atividade de porfirinas por nanoestruturas lipídicas também tem sido obtida para hemeproteínas uma vez que nanoestruturas lipídicas afetam a conformação das proteínas.
\end{abstract}

The structural factors modulating porphyrin activity encompass pyrrole and equatorial ligands, as well as the central metal and the number and structure of their axial ligands. Of equal importance is the microenvironment provided by apoproteins, solvents and membranes. Porphyrins are often used to construct supramolecular structures with different applications. The modulation of activity of the porphyrins has been frequently achieved by mimicking nature, i.e., by the provision of different microenvironments for these molecules. The association of porphyrins to surfactant- and lipid-containing nanostructures has changed the activity of these compounds to mimic different enzymes such as SOD, cytochrome P450, peroxidases and others. In determined conditions, the reactive forms of the porphyrins are high-valence states of oxo-metal- $\pi$ cations and oxo-metal produced by the reaction with peroxides and peracids. The modulation of porphyrin activity by surfactant- and lipid-containing nanostructures has also been achieved for hemeproteins, as the lipid nanostructures affect the conformation of proteins.

Keywords: porphyrin, micelles, liposomes, nanostructures

\section{Introduction}

Porphyrins are aromatic heterocyclic macrocycles derived from a moiety formed by four pyrrole rings interconnected by methine bridges. The pyrrole nitrogen atoms are able to coordinate a transition metal to be able to accept two axial ligands. Porphyrins and their derivatives participate in a diversity of biological processes, including

*e-mail: ilnantes@ufabc.edu.br cell respiration, detoxification of xenobiotics, oxygen transport, peroxide cleavage, $\mathrm{NO}^{\bullet}$ (nitric oxide) synthesis, fatty acid oxidation and light harvesting. ${ }^{1,2}$ In particular, protoporphyrin IX is a common prosthetic group of hemoglobin and of a diversity of enzymes, such as the antioxidant enzyme catalase and cytochrome $\mathrm{P} 450$, which is responsible for the reactions of hydroxylation of saturated carbon, the epoxydation of double bonds, the oxidation of heteroatoms, desalkylation and the oxidation of aromatic compounds. $^{3}$ 
The study of synthetic porphyrins has also gained interest due to their catalytic properties. Different derivatives of synthetic porphyrins have been obtained to attain long-living species and improved catalysts. ${ }^{4-8}$

Various factors influence the activity of metaloporphyrins. The structural factor modulating porphyrin activity encompasses pyrrole and equatorial ligands, as well as the central metal and the number and structure of their axial ligands. Equally important for the activity of porphyrin is the microenvironment provided by apoproteins, solvents and membranes. ${ }^{2,9}$

Porphyrins commonly form aggregates in aqueous media due to $\pi$ - $\pi$ interactions and hydrophobicity, and the association of these compounds to lipid nanostructures is one of the strategies to prevent the formation of aggregates..$^{10}$ Furthermore, the microenvironment created by lipid nanostructures provides an increase of the local substrate concentration and catalyst and, thus, improves the catalytic activity of the porphyrins. ${ }^{11}$

Lipid structures constitute an appropriate support for catalysts and present a potential application in biological media. The presence of neutral or charged interfaces and hydrophobic domains allows the association of molecules with different degrees of hydrophobicity and facilitates the interaction with biological membranes and their mimetics. ${ }^{12}$

The systems comprised of lipid nanostructures and porphyrins can be prepared by different experimental strategies, according to the desired type of lipid structure and properties. ${ }^{13}$ The complexes formed by micelles and porphyrins can be obtained by using different types of surfactants above the critical micellar concentration (CMC). Table 1 shows different surfactant types with their corresponding CMC values.

Different types and size of liposomes can be obtained by different techniques. ${ }^{13}$ Multilamellar vesicles (MLV) were the first liposome preparation to be described in detail and are the most widely used.$^{20}$ The preparation of MLV is simple, considering that the bilayer organization of phospholipids and synthetic lipids is a spontaneous process. The lipids are deposited from organic solvents in a thin film on the wall of a round bottom flask by rotary evaporation, under reduced pressure, or by purging nitrogen or argon concomitant with manual flask rotation. To obtain liposomes containing a mixture of lipids, the appropriate amount of the components should be mixed in the organic solvent prior to the deposition. Following this, an aqueous buffer is added, and the lipids are hydrated at a temperature above the transition temperature of the lipid or above the transition temperature of the highest melting component in the mixture. A thin film of lipid is desirable to facilitate the efficient hydration of the bilayer.
To obtain small unilamelar liposomes (SUV), the usual MLV preparation is subsequently sonicated either with a bath type sonicator ${ }^{21,22}$ or a probe sonicator under an inert atmosphere (usually nitrogen or argon). ${ }^{23-26} \mathrm{SUV}$ can also be obtained by the extrusion of hydrated lipid films. ${ }^{27}$ With this method, the liposome size is controlled by the pore filter. The preparation of phospholipid vesicles can also be achieved by the removal of detergents from detergentphospholipid mixtures, which results in the formation of unilamellar vesicles. This method has been widely used for the reconstitution of membranes. ${ }^{28,29}$ An alternative method for the preparation of small unilamellar vesicles that avoids both sonication and detergents is the ethanol injection technique described by Batzri and Korn. ${ }^{30}$ This technique consists of the rapid injection of lipids dissolved in ethanol into a buffer solution, where they spontaneously form small unilamellar vesicles. This procedure is simple, rapid, and gentle. Another technique based on the use of organic solvents is the ether infusion technique, introduced by Deamer and Bangham. ${ }^{31}$ Large unilamellar vesicles can also be formed from water-in-oil emulsions of phospholipids and buffer in an excess organic phase, followed by the removal of the organic phase under reduced pressure. ${ }^{32}$

\section{Protoporphyrin IX and Synthetic Porphyrins}

The properties of porphyrins and derivatives, such as redox potential, axial ligation, light gathering capacity and energy transducing, can be modulated by the out-of-plane distortions of these flexible chromophores. ${ }^{1}$ In this regard, the conformation and activity of porphyrins and derivatives can be influenced by axial ligands and their association with lipid aggregates, such as micelles and liposomes. ${ }^{1,33} \mathrm{As}$ models mimicking enzymes and for the development of new catalysts, porphyrins associated with lipid aggregates, such as aqueous and reverse micelles and liposomes, have been the focus of various studies. Metaloporphyrins associated with lipid nanostructures have been described as being able to act as models of peroxidases, superoxide dismutase, cyclooxigenase and cytochrome P-450..$^{2,34}$ Generally, the activation of the porphyrin moiety to a catalytically active species, or the metal-oxo form, is obtained by a reaction with hydrogen peroxide, organic peroxides and peracids. ${ }^{35-40}$

The reactive species metal-oxo porphyrin (Figure 1), produced by the reaction with hydrogen peroxide, is effective as a catalyst of olefine epoxidation..$^{4-47}$

Data from the literature reports an increase of the reaction specificity when the porphyrin is associated with lipid structures, since the epoxidation products predominate in this condition. ${ }^{18}$ Figure 2 shows the general mechanism of epoxidation promoted by porphyrins. 
Table 1. Possible main surfactants to be used for the association of porphyrins with micelles

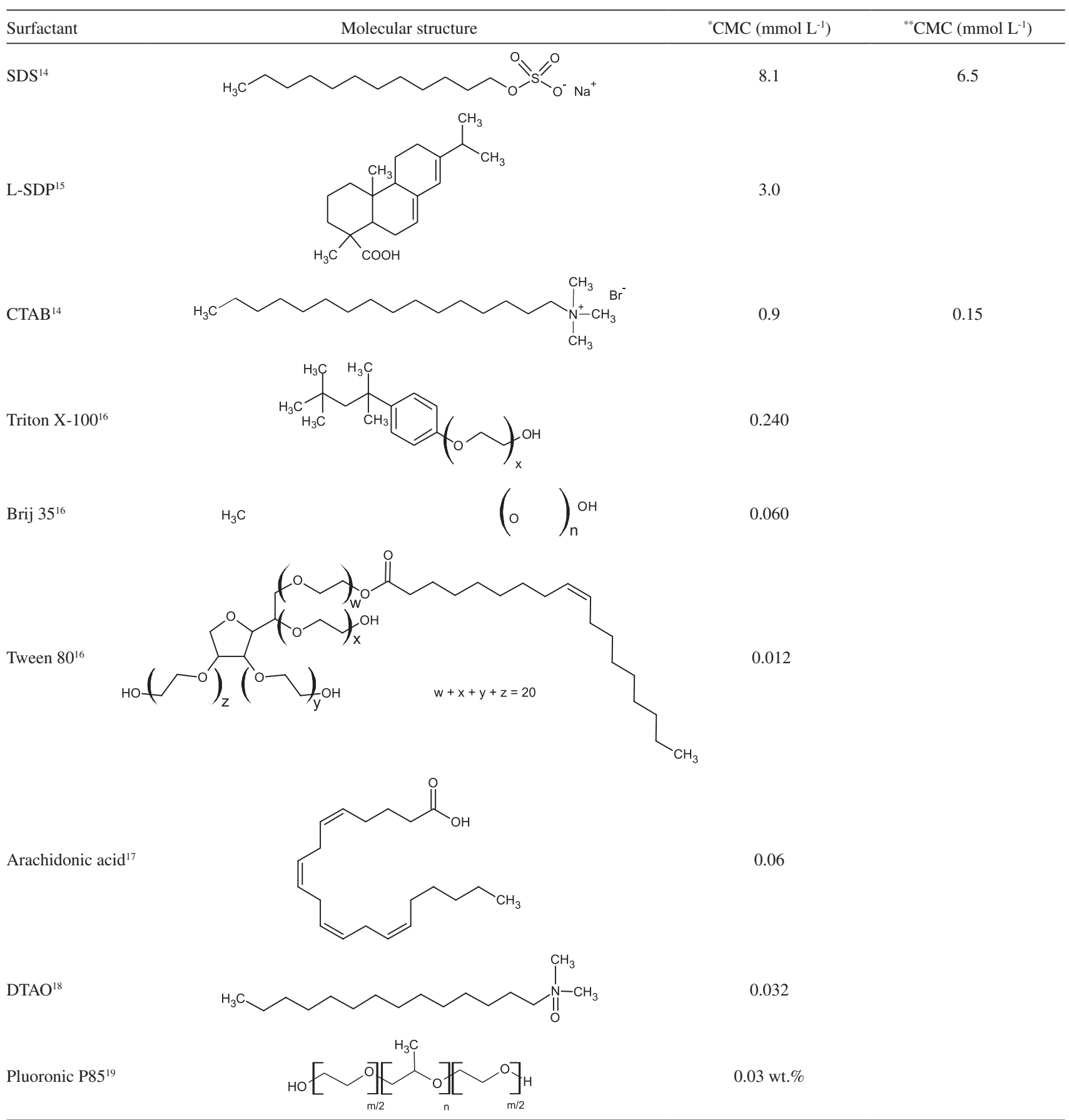

*Pure water, **10 $\mathrm{mmol} \mathrm{L}^{-1}$ salt, when salt is the counterion.

Moreover, the association to micelles leads to an increase of substrate specificity. ${ }^{48-50}$ Apart from the chemical catalysis, the photoactivation of porphyrin/lipid aggregates has also been described. ${ }^{18}$ The photocatalysis process conducted by porphyrins is based on the generation of excited states of these molecules, followed by electronor energy-transfer reactions able to trigger the chemical reactions of interest (Figure 3).
In the homogeneous phase, $\mathrm{Fe}^{3+}$ porphyrin complexes are able to photocatalyze the oxidation of alkanes and alkenes. The general mechanism involves photoexcitation in the wavelength range of the axial ligand to metal chargetransfer bands, which leads to the homolytic cleavage of the $\mathrm{Fe}^{3+}$-ligand bond followed by the oxidation and the detachment of the ligand as a radical species and the reduction of $\mathrm{Fe}^{3+}$ to $\mathrm{Fe}^{2+}$. The ligand-derived free radical 
Table 2. Possible main surfactants to be used to associate liposomes with porphyrins

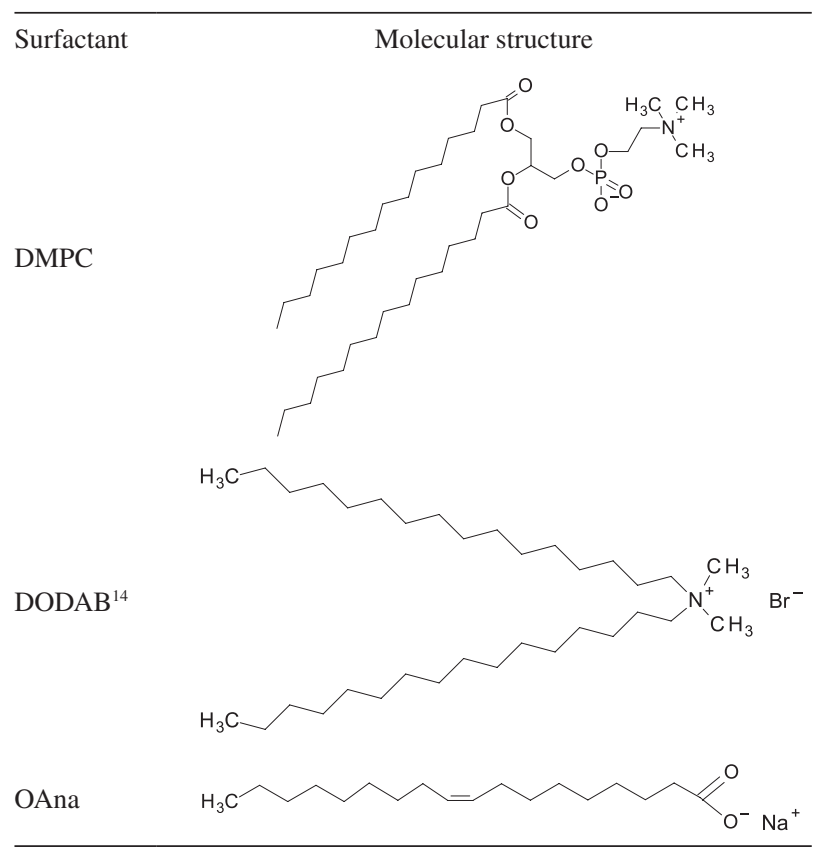

oxidizes the alkanes and alkenes leading to, in the presence of oxygen, the formation of peroxy derivatives and radical propagation. ${ }^{18}$ The photocurrent generation from porphyrin/ fullerene complexes is an important application and appears as an innovation in the existing photovoltaic systems. ${ }^{51}$

Interesting results have been obtained with organized molecular systems, in which porphyrins are associated to polymers and lipid nanostructures, in a biomimetic approach to induce hydrocarbon oxofunctionalization. An interesting example is the association of $\mathrm{Fe}^{3+}$ TDCPP ( $\mathrm{Fe}^{3+}$ meso-tetrakis(2,6-dichlorophenyl)-porphyrin) to micellar aggregates. ${ }^{18}$ Aqueous solutions of DTAO ( $N, N$-dimethyltetradecylamine $N$-oxide) are able to dissolve both $\mathrm{Fe}^{3+} \mathrm{TDCPP}\left(2 \times 10^{-5} \mathrm{~mol} \mathrm{~L}^{-1}\right)$ and considerable amounts of cyclohexene or cyclooctene (up to $5 \times 10^{-2} \mathrm{~mol} \mathrm{~L}^{-1}$ ). The irradiation of the system in the presence of oxygen leads to the formation of cyclohex-2-en-1-one as a main oxidation product of cyclohexene. The reaction is favored because the location of the porphyrin in the nonpolar region of the micelles, where the heterolytic cleavage of the $\mathrm{Fe}^{3+}$ porphyrin cyclohexenyl peroxide intermediate occurs, is not favored. The complex substrate and the catalyst undergoes intramolecular decomposition, inciting the starting $\mathrm{Fe}^{3+}$ porphyrin complex and the corresponding ketone. Cyclohexene and cyclooctene are also oxidized to the corresponding epoxides, and the system exhibits a selectivity higher than $90 \%$ in the case of cyclooctene. One interesting study reported that Triton X-100 micellar solution was able to favor remarkble catalytic activity of manganese pyrochlorophyllide a, an effect similar to that exhibited by PEG (polyethylene glycol). The dramatic effects of lipid aggregates, such as aqueous and reverse micelles and liposomes, on the catalytic activity of porphyrins are associated with the alterations of symmetry and aggregation modes of these molecules, in which many factors are involved, including the concentration of

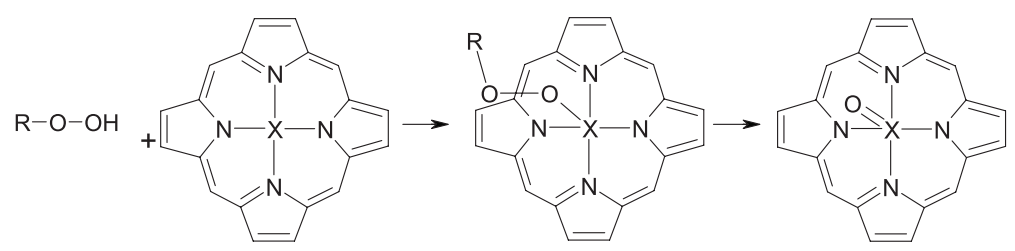

Figure 1. Schematic representation of the mechanism of preparation of the reactive species M-oxo porphyrin.



Figure 2. Schematic representation of the mechanism of alkene epoxidation catalyzed by metaloporphyrins. 




Figure 3. General mechanism of photocatalysis conducted by porphyrins.

porphyrin, the structure of porphyrin and the concentration of surfactants. ${ }^{35-39}$

One example of the effect of micellar aggregates on the structure of porphyrins is provided by the analysis of the UV-Visible (UV-Vis) and magnetic circular dichroism (MCD) spectral changes exhibited by the synthetic porphyrin $\mathrm{Fe}^{3+}$ TPFPP $\left(\mathrm{Fe}^{3+}\right.$ meso-tetrakis-1,2,3,4,5- pentafluorphenylporphyrin) after its association with charged micelles. The UV-Vis and MCD spectroscopy are extremely useful techniques to identify changes in the structure of porphyrins, as the electronic transitions occurring in these compounds are extremely sensible to the molecular structure and symmetry related to changes in the orbital energy. Particularly in the MCD technique, the use of left and right circularly polarized light ( $l c p$ and $r c p$, respectively) associated with the magnetic field allows researchers to obtain refined details about structural changes.

Metaloporphyrins present two types of electronic transitions resulting from light absorption: $\pi-\pi *$ transitions, occurring at the organic moiety, and $\pi$-d transitions, involving the porphyrin ring $\pi$ orbitals and the central metal d orbitals. These transitions contribute to the characteristic $\mathrm{Q}$ and Soret bands, a fingerprint of porphyrins and can be also evidenced in the corresponding MCD spectra (see band assignments in Figure 4A and 4B). The UV-Vis and MCD spectra of $\mathrm{Fe}^{3+}$ TPFPP, obtained in the respective anionic and cationic SDS and CTAB micelles and depicted in Figure 4, give evidence of an interesting effect of the medium on the orbital energy of porphyrins. The UV-Vis spectrum of $\mathrm{Fe}^{3+}$ TPFPP associated with CTAB micelles presents the typical porphyrinoid Q, Soret and $\mathrm{N}$ bands resulting from transitions, respectively, in ascending energies. In the electronic absorption spectra, the $\mathrm{N}$ band appears at around $30000 \mathrm{~cm}^{-1}$ and the Soret band at $25000 \mathrm{~cm}^{-1}$ in CTAB and SDS micelles. Figure 4A and 4B, light gray lines show the experimental UV-Vis and MCD spectra obtained in the presence of the surfactants CTAB and SDS, respectively. The UV-Vis spectra obtained in both conditions were decomposed to show the contribution of the overlapped transitions contributing to the spectral composite (thick black solid lines). The Soret band of the porphyrin in CTAB micelles is narrower than the spectrum obtained from SDS micelles, as a result of the difference in the energy of the transitions that contributes to the spectra in different media.

The MCD spectra of $\mathrm{Fe}^{3+}$ TPFPP in CTAB and SDS micelles also show significant differences according to peculiar structures exhibited by the porphyrin in different environments. The MCD spectroscopy was also useful to study the effect of the microenvironment on the structure of CD silent non-chiral porphyrins. In a non-chiral material optical activity is absent and the lcp and rcp transitions are not differentiated. The application of a magnetic fieldpromotes splitting of double degenerate ground $(\mid \mathrm{A}>)$ ) or 

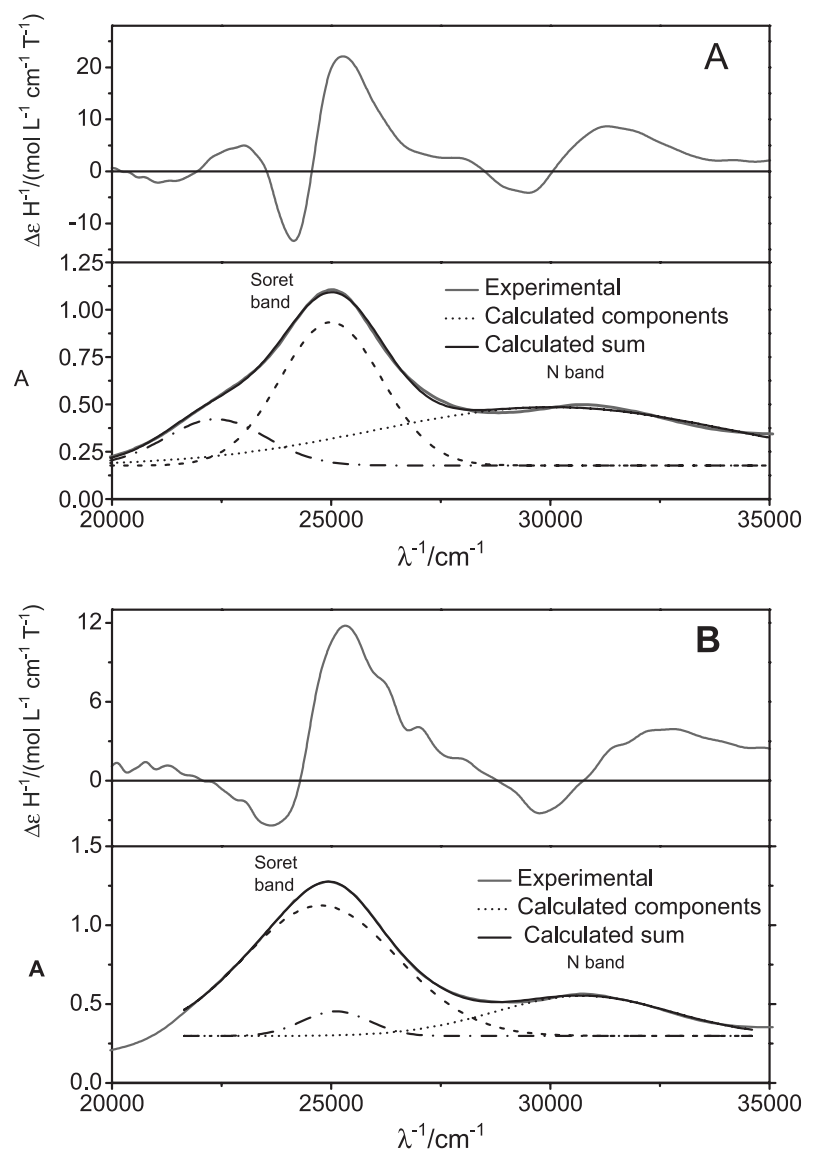

Figure 4. MCD (top panels) and UV-Vis (bottom panels) spectra of $\mathrm{Fe}^{3+}$ TPFPP in different media: A- CTAB micelles and B- SDS micelles. Both in $\mathrm{A}$ and $\mathrm{B}$, in bottom panels, solid gray lines represent the experimental data, dotted black lines represent the simulated spectral contributions and the solid black line the sum of the calculated spectral contributions. The simulation was done by the software Microcal Origin 8.1. Adapted from Figures 8 and 10 of reference 51.

excited $(\mid \mathrm{J}>$ ) states (Zeeman effect) or the combination of an intermediate state $(\mid \mathrm{K}>)$ with ground or excited states. Therefore, due to the Zeeman effect, optical activity is induced in the non-chiral material, since it differentiates the lcp and rep transitions (Figure 5). MCD transitions, associated with degenerate orbital splitting, exhibit a derivative band shape, with the zero-crossing coincident with the peak of the corresponding Soret and Q bands (Faraday $A$-term). On the other hand, MCD transitions associated with the mixing of an intermediate state $(\mid \mathrm{K}>)$ with ground or excited states, exhibit an absorption band shape (Faraday $B$-term). In a condition in which $\mathrm{kT} \gg g \beta H$ (splitting $\Delta \mathrm{E}$ ), the splitting of a double degenerate ground state by the magnetic field results in two spin sublevels that are equally populated. However, at low temperatures, when kT $c a . g \beta H$ only one spin sublevel is predominantly populated resulting in a MCD transition with an absorption band shape, called as $C$-term. However, temperature dependent MCD transitions are not always associated to degenerate orbital splitting. In a similar way, temperaturedependent MCD transition with absorption band shape can also result from the mixing of $\mid \mathrm{K}>$ with $\mid \mathrm{A}>$ being one sublevel predominantly populated at low temperatures. See Figure 5, for details about MCD spectroscopy. ${ }^{6,51}$

In the case of $\mathrm{Fe}^{3+} \mathrm{TPFPP}$, the MCD spectra obtained both in CTAB and SDS micelles exhibit a non-symmetrical derivative feature, due to the contribution of a Faraday $A$-term associated with the $\pi$-d transition overlapped with the positive and negative contribution of Faraday $B$-term associated with the $\pi-\pi^{*}$ transition. The Soret band peak and the zero crossing of the $\mathrm{Fe}^{3+}$ TPFPP MCD spectrum obtained in CTAB were the same as those obtained by the association with the anionic SDS micelles. Thus, apparently the charge of the micelle had no influence on the energy of the ligand to metal transition (LMCT). However, the association of $\mathrm{Fe}^{3+}$ TPFPP with SDS micelles led to changes in the energy levels of $\pi-\pi *$ transitions. SDS micelles promoted a higher separation of the vibrational levels, resulting in a broader Soret band. The changes in the energy levels of the $\mathrm{Fe}^{3+} \mathrm{TPFPP} \pi-\pi^{*}$ transitions led to a higher overlap of the positive envelope of the Faraday $B$-term on the negative envelope of the LMCT bands at the spectral regions of the $\mathrm{Q}$ and Soret bands. Therefore, UV-Vis and MCD spectroscopy give evidence that the microenvironment provided by different micelle types have a strong influence on the structure and, consequently, on the catalytic activity of the porphyrins.

The different microenvironments provided by the lipid nanostructures, as well as the symmetry and structural changes, contribute to modulate the catalytic activity of the pophyrins. Furthermore, data from the literature shows that the ionization $\mathrm{pK}_{\mathrm{a}}$ of the water molecule at the sixth coordination position of the central metal is drastically modified when the porphyrin is associated with charged interfaces. In the case of positively charged interfaces, the lowering of the coordinated-water $\mathrm{pK}_{\mathrm{a}}$ value favors the peroxidase activity of the porphyrins. ${ }^{52}$ Another important aspect to be considered is the impairment of porphyrin aggregation when they are associated with micelles, and this effect is also observed when porphyrins are associated with lipid bilayers. ${ }^{53-55}$ Therefore, its association with lipid nanostructures can give to synthetic porphyrins catalytic properties similar to those of hemeproteins. ${ }^{56-59}$

The peroxidase activity of metaloporphyrins associated with lipid nanostructures has been also used for therapeutic applications. Metaloporphyrins associated with liposomes have been used for cancer treatment as inducers of oxidative stress and cell death. The mechanism to induce cell death is the generation of a hydroxyl radical from the peroxide cleavage. ${ }^{60,61}$ 


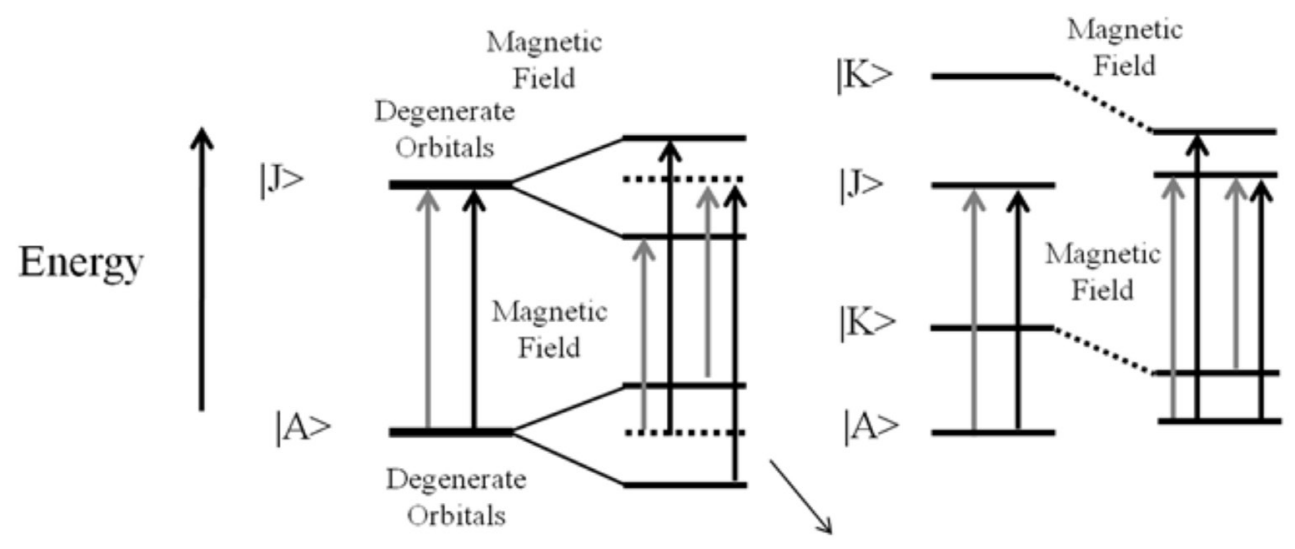

Faraday $C$-term when $\mathrm{kT} \sim \mathrm{g} \beta H$

Faraday $A$-term

Faraday $B$-term

Figure 5. Molecular orbitals, splitting and mixing, promoted by the magnetic field, resulting in the MCD spectral contribution of Faraday $A$ - and $B$-terms, respectively. Lcp and rcp are represented by gray and black arrows, respectively. At left, the splitting of degenerate orbitals by the magnetic field (Zeeman effect) results in the lcp and rcp transitions with different energies. When kT $c a . g \beta H$ the associated transition is dependent of temperature (Faraday $C$-term). At right, the mixing of an intermediate state $(\mid \mathrm{K}>)$ with ground or excited states also results in the lcp and rep transitions with different energies and the mixing of $\mid \mathrm{K}>$ with $\mid \mathrm{A}>$ can result in a temperature-dependent transition. In both conditions, Zeeman effect and magnetic field-induced mixing of states, a CD silent molecule exhibits a MCD signal.

\section{Hemepeptides}

Microperoxidases are hemepeptides produced by the sequential pepsin- and trypsin-catalyzed hydrolysis of the horse-heart cytochrome $\mathrm{c}$. The resulting structure retains the heme group covalently attached to cysteine residues 14 and 17 and with histidine 18 as the fifth axial ligand. ${ }^{62-64}$ According to the sequence of native cytochrome $\mathrm{c}$, from which these peptide fragments are derived, it is possible to obtain four microperoxidase types: microperoxidase- 6 (CAQCHT), microperoxidase-8 (MP-8) (CAQCHTVE), microperoxidase-9 (MP-9) (KCAQCHTVE) and microperoxidase-11 (VQKCAQCHTVE). The efficient peroxidase activity of microperoxidases results from the loss of the methionine 80 residue at the sixth coordination position. ${ }^{62-64}$ Figure 6 shows the structure of microperoxidase 9 .

These hemepeptides are able to form the same enzyme intermediates during the reaction with peroxides and have been largely used as attractive water-soluble models to study the reaction mechanism of peroxidases. Micelles of CTAB, a cationic surfactant (Table 1), provide a microenvironment



Figure 6. Structure of microperoxidases MP9. 
with an alkaline interface and a hydrophobic core that modify the structure and spectral properties of $\mathrm{Fe}^{3+}$ microperoxidases, as compared to a homogeneous medium (Table 3). ${ }^{56}$ These structural modifications have repercussions on the catalytic activity of the hemepeptides.

Table 3. Effect of CTAB on the spectral characteristics of $\mathrm{Fe}^{3+}$ microperoxidase- 8

\begin{tabular}{lccc}
\hline Species & $\begin{array}{c}\text { Soret band } \\
(\mathrm{nm})\end{array}$ & $\begin{array}{c}\text { Q-bands } \\
(\mathrm{nm})\end{array}$ & $\begin{array}{c}\text { CT band } \\
(\mathrm{nm})\end{array}$ \\
\hline MP-8 compound II & 406 & 519 and 548 & $581 *$ \\
MP-8 compound II/CTAB & 409 & 517 and 543 & \\
$\mathrm{Fe}^{3+} \mathrm{MP}-8$ & 396 & 494 & 622 \\
$\mathrm{Fe}^{3+} \mathrm{MP}-8 / \mathrm{CTAB}$ & 400 & 485 and 520 & 584 \\
\hline
\end{tabular}

* The CT (charge-transfer) band at 581 is substituted by a shoulder at the same wavelength, when compound II is generated by $t-\mathrm{BuOOH}^{56}$

In a series of studies, we have demonstrated that the association of $\mathrm{Fe}^{3+} \mathrm{MPs}$ with CTAB micelles gives to the hemepeptides the characteristics of a true enzyme, as they became capable of discriminating substrates ${ }^{56,65}$ exhibiting catalytic cycles without catalyst degradation, and controlling the route of the reaction with diphenylacetaldehyde. ${ }^{66}$

The structure of MPs has a net negative charge, due to the presence of heme propionate groups and the carboxy group of the C-terminal oligopeptide chain, which are responsible for the electrostatic affinity for the cationic CTAB micelle surface. However, the hydrophobic groups present in the oligopeptide chain with the hydrophobic heme group also cause a significant affinity for the micelle core. Thus, a model for MPs associated with CTAB micelles was proposed, in which the heme propionate groups are associated with the micelle surface and the porphyrin ring and oligopeptide side chains are partially inserted into the micelle.

Microperoxidases associated with CTAB micelles exhibit the red shift of the Soret band that is typical of the heme group in a hydrophobic microenviroment. ${ }^{67}$ Changes in the EPR parameters for the high spin state of MPs suggest that inside the micelle, the hemepeptides are not coordinated with water but probably instead with $\mathrm{OH}^{-}$or with the $\varepsilon$-amino group of its $N$-terminal lysine residue. The intra-chain coordination with the $N$-terminal lysine residue was demonstrated for MP-9 in solution. ${ }^{68}$

In the complex with the MPs, the micelle constitutes an artificial enzymatic active site that exhibits a higher affinity for hydrophobic substrates. MP-9/CTAB and MP-8/CTAB complexes exhibit different affinities for $t$ - $\mathrm{BuOOH}$ (tertbutylhydroperoxide) and $\mathrm{HOOH}$. MP-9/CTAB behaves as a true peroxidase and exhibits a peroxidase catalytic cycle during its reaction with $t-\mathrm{BuOOH}$. In this way, this heme peptide/micelle aggregate behaves as an artificial enzyme that was named lipoenzyme. The catalytic cycles observed when peroxide was the only available substrate are depicted in Figure 7. ${ }^{69,70}$

Primus et al. ${ }^{71}$ described the formation of the MP- 8 compound II in the presence of high $\mathrm{HOOH}$ concentrations $\left(0.2-1.2 \times 10^{-3} \mathrm{~mol} \mathrm{~L}^{-1}\right)$ in homogeneous media. In this system, the catalyst was progressively inactivated to a species that exhibited Soret band bleaching. In the presence of CTAB micelles and high peroxide concentrations (0.2$1.2 \times 10^{-3} \mathrm{~mol} \mathrm{~L}^{-1}$ ), we have identified the occurrence of the same process for MP-8 and MP-9, suggesting that, both in a homogeneous medium and as associated with CTAB micelles, MP-8 and MP-9 compounds I are able to oxidize $\mathrm{HOOH}$ to produce compound II.

The occurrence of an oxidative attack and the bleaching of the heme group or a reversible peroxidase cycle without the degradation of the catalyst are dependent on the hemepeptide/micelle ratio and the peroxide concentration. However, whatever the conditions, an association with CTAB micelles favors the formation of the high-valence intermediate oxoferryl. ${ }^{71}$ As shown in Figure 7, the formation of high-valence intermediates of peroxidases is preceded by the coordination of a deprotonated peroxide molecule with the heme iron, leading to a complex that is known as compound 0 (Figure step 1). The deprotonation of the hydroperoxide in compound 0 is a crucial step in the catalytic cycle of peroxidases and cytochrome P450, and consequently, protons act as competitive inhibitors for the reaction. ${ }^{71}$ In horseradish peroxidase, the distal His42 ligand acts as an acid/base catalyst that favors the deprotonation of the hydroperoxide substrate at the enzyme active site and the subsequent heterolytic cleavage of the peroxide..$^{72-74}$ Differing from those of horseradish peroxidase, MPs in an aqueous medium do not exhibit a site pocket with a distal basic residue participating in the peroxide deprotonation and favoring the $\mathrm{O}-\mathrm{O}$ peroxide bond cleavage. These characteristics should be the cause for the low reactivity of the hemopeptides at low $\mathrm{pH}$ values. In an aqueous medium, the alkaline $\mathrm{pH}$ leads to the deprotonation of the MP bound water, which then either assists concerted hydrogen peroxide deprotonation and coordination of the hydroperoxo group to the metal center or is directly oxidized by hydrogen peroxide to a metalhydroperoxo $\mathrm{MP}^{71}$

In the presence of CTAB micelles, the enzymatic cycle occurs efficiently at $\mathrm{pH}$ 7.4. The micellar alkaline interface favors the deprotonation of the water molecule bound to heme iron and subsequent change of the substrate molecule with the formation of a MP compound 0 (Figure 5, step 1). In the following, there are two possible mechanisms for 


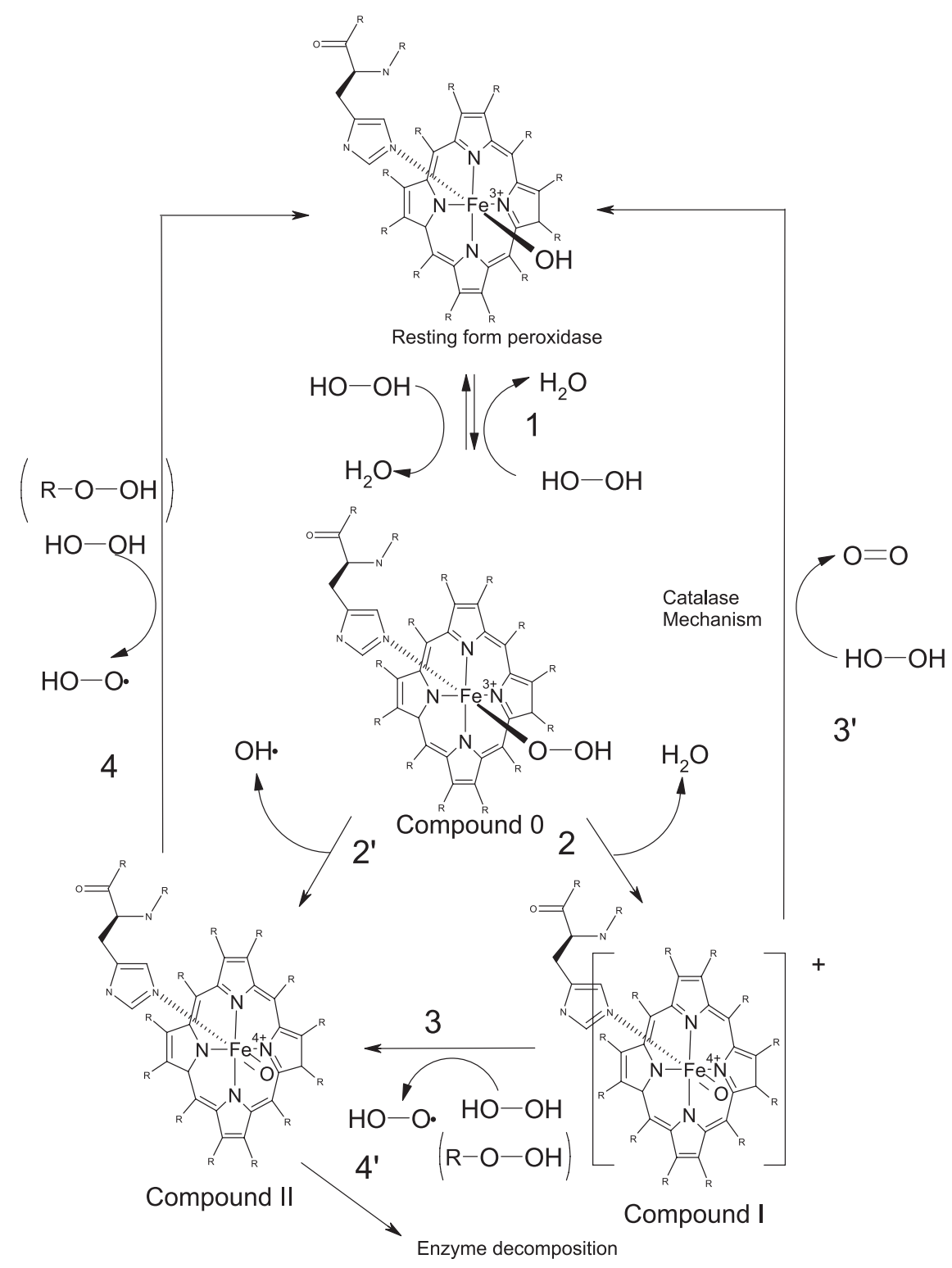

Figure 7. Compound 0 is formed after the reversible coordination of heme iron with the peroxide. Heterolytic cleavage of the peroxide results in the formation of compound I (oxoferryl- $\pi$ cation form). The two-electron reduction of compound I by hydrogen peroxide regenerates the resting enzyme through a catalase mechanism, and one-electron reduction by a peroxide molecule results in compound II (the oxoferryl form). Compound II can be reduced by another peroxide molecule to regenerate the resting enzyme. The homolytic cleavage of peroxides generates the compound II hydroxyl radical. In the presence of an excess of peroxide, progressive enzyme inactivation is observed as pointed by reference 70 .

the cleavage of peroxides $(\mathrm{ROOH})$ : a heterolytic cleavage, generating the alcohol derivative ( $\mathrm{ROH})$, and compound I (Figure 7, step 2), which reacts with another peroxide molecule, generating compound II and the peroxyl radical ROO• (Figure 7, step 3) or a homolytic cleavage of ROOH to form compound II directly (Figure 5, step 3'). In any case, native $\mathrm{Fe}^{3+} \mathrm{MP}$ is regenerated after the reaction of compound II with another ROOH molecule (Figure 7, step 4), and the catalytic cycle is guided to completion. The recycling of MP high-valence species to the resting form in the $\mathrm{MP} / \mathrm{CTAB}$ micelle complex is evidence that this system behaves as a true peroxidase. As a result, the MP/CTAB micelle complex is an interesting model to study peroxidase reaction mechanisms and to be applied in nanotechnological devices as a replacement of biological peroxidases.

The complex $\mathrm{Fe}^{3+} \mathrm{MP}-9 / \mathrm{CTAB}$ is also able to oxidize aldehydes such as diphenylacetaldehyde. ${ }^{56}$ It was demonstrated that the association of $\mathrm{Fe}^{3+} \mathrm{MP}-9$ and $\mathrm{Fe}^{3+} \mathrm{MP}-11$ with CTAB micelles (MP-9/CTAB and MP11/CTAB) provides a microenvironment that shifts positively the redox potential of microperoxidases by $c a$. $100 \mathrm{mV}$. The addition of diphenylacetaldehyde (DPAA) to the MP-9/CTAB compound II regenerated the native form of the enzyme, $\mathrm{Fe}^{3+} \mathrm{MP}-9 / \mathrm{CTAB}$, and is what characterizes 
the occurrence of a peroxidase cycle. Furthermore, $\mathrm{Fe}^{3+} \mathrm{MP}-9 / \mathrm{CTAB}$, regenerated during the peroxidase cycle, reacted with residual DPAA in the medium and was converted to $\mathrm{Fe}^{2+} \mathrm{MP}-9 / \mathrm{CTAB}$, which indicates that both $\mathrm{Fe}^{3+} \mathrm{MP}-9 / \mathrm{CTAB}$ and its oxyferryl form can use aldehydes as reducing agents. The reaction of MP-9/CTAB with DPAA produced benzophenone as final product, and a significant difference was observed in the benzophenone yield, according to the micelle/MP-9 molar ratio. The yield of the product reaction of MP-9/CTAB with DPAA, benzophenone, was dependent of the micelle/MP-9 molar ratio. This difference was assigned to the accessibility of the MP-9 amino group to the aldehyde. Spectral analysis showed that the decrease of the micelle/MP ratio favors the association of hemepeptide pairs with the micelle. In a dimeric association with CTAB micelles, Lys13 amino groups could be forced to be located outside of the micelle, where the concentration of DPAA was significantly lower due to the partition of the aldehyde, preferentially inside the micelle core. However, in the monomeric form, it is expected that the Lys13 amino groups are to be found inside the micelle core and, thus, are prone to react with DPAA, leading to the formation of Schiff base adducts. Furthermore, in the monomeric form, the peptide chain of MP-9 should be inside the micelle and, thus, is prone to be attacked by intermediate free radicals formed in the course of the reaction. The trapping of the intermediate radicals contributes to the decreasing of the yield of benzophenone without the impairment of the heme iron reduction, a process that precedes the formation of these radicals.

\section{Hemeproteins}

In cells, the association of apoproteins with the iron protoporphyrin IX, the heme group, is a strategy to modulate its biological properties. The apoproteins provides a variety of microenvironments and axial ligands in such a way that the heme group is able to coordinate molecular oxygen and $\mathrm{NO}^{\bullet}$ for storage as a transport well and, furthermore, to participate in electron transport, peroxide cleavage, hydroxylation, epoxidation, and NO• synthesis, among other activities. However, even in the case of hemeproteins, the association with lipid nanostructures, such as micelles and liposomes, can change the properties of the porphyrin. In this review, we present two hemeproteins whose activity is modulated by their association with micelles and liposomes: horseradish peroxidase (HRP) and cytochrome c.

HRP $C$ is an acidic hemeprotein that exhibits affinity for the cationic CTAB micelles and DODAB liposomes. These surfactants promote structural changes in the HRP structure, leading to the enhancement of the enzyme activity on the aldeydes: PPA (2-phenylpropionaldehyde) and DPAA. ${ }^{75}$ Otherwise, the alkaline hemeprotein, cytochrome c, exhibits a low affinity to cationic interfaces but is highly susceptible to the effects of acidic surfactants such as SDS, AOT and cardiolipin..$^{77,76}$ The association of cytochrome c with the anionic aqueous and reverse micelles, SDS or AOT/hexane, respectively, leads the heme group of the protein to a less rhombic symmetry that is characterized by electron paramagnetic resonance, UV-Vis, CD, magnetic CD, fluorescence, and Raman resonance. ${ }^{57}$ In this condition, the replacement of Met80 by another strong field ligand, probably Lys79, was detected. The cytochrome c species obtained with these anionic surfactants was named as alternative low-spin state cytochrome c (ALSScytc). The ALSScytc retained the capacity to cleave tertbutylhydroperoxide and to be reduced by dithiothreitol and diphenylacetaldehyde, but not by ascorbate. Compatible with a more open heme crevice, ALSScytc exhibited a redox potential that was approximately $200 \mathrm{mV}$ lower than the wild-type protein $(+220 \mathrm{mV})$ and was more susceptible to the attack of free radicals. ${ }^{57}$

When associated with negatively charged liposomes, cytochrome c establishes both electrostatic and lipid extended interactions. ${ }^{77}$ In a systematic study, ${ }^{57}$ a clear correlation between the nature of the lipid acyl chain and the spin states of cytochrome $\mathrm{c}$ interacting with different types of lipid membranes was shown. Three spin states of cytochrome c were observed in different proportions, according to the lipid acyl chain type and the head group charge present in the bilayer: a native cytochrome $\mathrm{c}$ low-spin state with rhombic symmetry, a low-spin state with less rhombic symmetry, and a high spin state. The proportion of the spin states of cytochrome $\mathrm{c}$ that were bound to bilayers was also dependent on the lipid/protein ratio. This result suggested the existence of two or more protein sites interacting with the lipids, which was further corroborated. ${ }^{77,78}$ In the complex with acid lipids, due to the insertion of a lipid acyl chain inside the cytochrome $\mathrm{c}$ structure, this hemeprotein becomes a more efficient peroxidase and can even react with lipid peroxide derivatives. ${ }^{79-82}$

\section{Conclusion}

Lipid- and surfactant-containing nanostructures, such as micelles and liposomes, are able to modulate the activity of biological and synthetic porphyrins. The surfactant aggregates are able to influence the porphyrin activity due to several factors: changes in the symmetry of the ring, the replacement of axial ligands, the favoring or disfavoring of porphyrin aggregation, changes in the redox potential, and 
the selectivity of substrate access to the catalytic center. Even for hemepeptides and hemeproteins, micelles and liposomes still have a significant influence on the activity of the porphyrin, as they are able to change peptides, the protein structure and the axial ligands, as well as modulate and select access of substrates. Given these properties, surfactants are attractive devices to construct catalysts with porphyrins and their derivatives.

\section{Acknowledgments}

Support from FAPESP, CNPq and CAPES are acknowledged. We are grateful to Professor Otaciro R. Nascimento for the discussions about magnetic circular dichroism theory. Professors ILN and ND are grateful to the students, co-authors of the present article, who participated in the Nanotechnology course of the Graduate Program in Science and Technology/Chemistry of UFABC and who were evaluated by their contributions to this review.

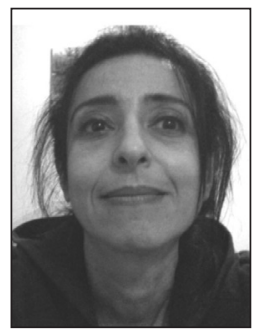

Iseli L. Nantes is a Professor of Bioenergetics at the Universidade Federal do ABC-UFABC. She received her $P h D$ at the University of São Paulo (USP) working on the enzymatic generation of excited states in model systems, chloroplasts and mitochondria (1995), under the supervision of Professor Giuseppe Cilento. She completed her Postdoctoral research at the University of Campinas (UNICAMP) and USP (1995-1998) and became a Professor of Biochemistry at the University of Mogi das Cruzes (1998-2009). In 2009, she joined UFABC as a Full Professor of Bioenergetics, her present position. Her present research interests are the structure and functions of porphyrins, hemepeptides and hemeproteins. She is investigating the development of porphyrin-containing nanocatalysts as well as the effects of porphyrins and hemeproteins, particularly, cytochrome $c$ and derivates on the mechanisms of cell death. She is the Coordinator of Thematic and a Multi-user Facilities projects, both of them granted by the Fundação de Amparo à Pesquisa do Estado de São Paulo (FAPESP).

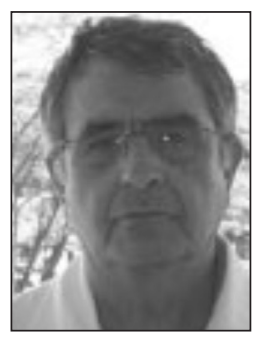

Nelson Durán is a Professor of Chemistry at the University of Campinas (UNICAMP) (Brazil) and a visiting professor at the Universidade Federal do $A B C-U F A B C$. He received his PhD from the University of Puerto Rico (USA) working on the photolysis and thermolysis of 1,2-dioxolanes (1972). He was an Associate Professor at the Universidad Catolica de Valparaiso, Chile (1973-1975) and carried out a Visiting Professorship at Universidade de São Paulo, Brazil (1975), investigating enzymatic generation of excited states intermediates. In 1978, he joined the Chemistry Institute of UNICAMP (Brazil), working in Biological Chemistry and Biotechnology. His present research interests are nanobiotechnology in cosmetics and in pharmaceuticals, in addition to metallic nanoparticles as antibiotics carriers. He is the Coordinator of the Brazilian Nanobiotechnology Network and a member of the Brazilian Nanocosmetics and Carbon Nanotubes Networks and of the Committee of Brazil-Argentina Nanotechnology Center and belongs to the Consultant Committee for the Nanotechnology area in the Brazilian Science and Technology Ministry.

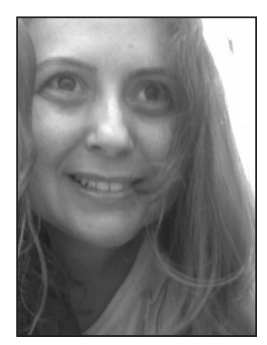

Sandra Marilia de Souza Pinto obtained a BSc in Biological Sciences from the Centro Universitário Augusto Motta (2005) and a MSC degree from the Universidade Federal de São Paulo (2009). Currently, she is a PhD student of the Biosystems Graduate Program at the Universidade Federal do ABC (UFABC).

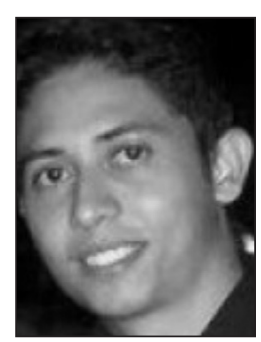

Roberto Alves de Sousa Luz obtained a BSC in Chemistry (2007) and a MSc degree from the Universidade Federal do Piauí. Currently, he is a PhD student of the Chemistry Graduate Program at the Universidade Federal do ABC.

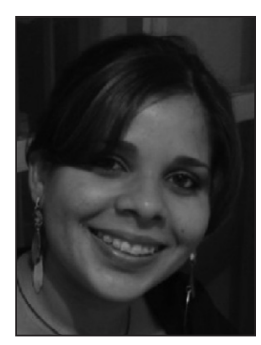

Juliana dos Santos de Souza obtained a BSc in Chemistry (2007) from the Universidade Estadual de São Paulo (2008). Currently, she is an MSc student of the Chemistry Graduate Program at the Universidade Federal do $A B C$.

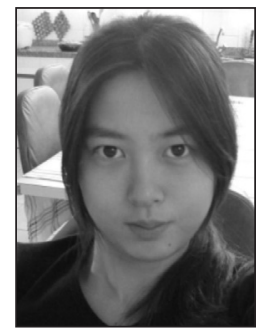

Noemia Isoda obtained a BSC in Chemistry Engineering from the Escola de Engenharia de Lorenal USP (2008). Currently, she is an MSc student of the Chemistry Graduate Program of the Universidade Federal do $A B C$. 


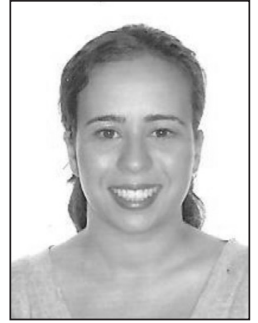

\section{Tiara Gomes de Oliveira obtained} a BSc in Food Engineering from the University of São Paulo (2008). She participated in the Nanotechnology course as a special student.

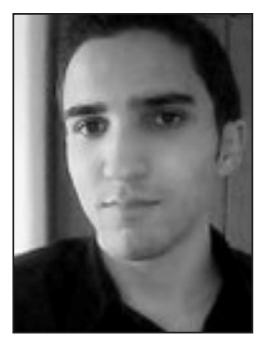

Vinícius Godoi Fernandes obtained a BSc in Biomedicine from the Bandeirante University of São Paulo (2009). He participated in the Nanotechnology course as a special student.



Fabiana Braz da Silva obtained a BSc in Chemistry: Graduate Teacher Programme with Technological Assignment from the Sao Bernardo do Campo College (2007). She participated in the Nanotechnology course as a special student.

\section{References}

1. Drain, C. M.; Varotto, A.; Radivojevic, I.; Chem. Rev. 2009, $109,1630$.

2. Aida, T.; Inoue, S. In The Porphyrin Handbook; Kadish, K. M. Smith, K. M. Guillard R., eds.; Academic Press: San Diego, 2000, ch. 42.

3. Ponka, P.; Am. J. Med. Sci. 1999, 318, 241.

4. Da Silva, D. C.; De Freitas-Silva, G.; do Nascimento, E.; Rebouças, J. S.; Barbeira, P. J.; de Carvalho, M. E.; Idemori, Y. M.; J. Inorg. Biochem. 2008, 102, 1932.

5. Bochot, C.; Bartoli, J. F.; Frapart, Y.; Dansette, P. M.; Mansuy, D.; Battioni, P.; J. Mol. Catal. A.: Chem. 2007, 263, 200.

6. Alkordi, M. H.; Liu, Y. L.; Larsen, R. W.; Eubank, J. F.; Eddaoudi, M.; J. Am. Chem. Soc. 2008, 130, 12639.

7. Suijkerbuijk, B.; Schamhart, D. J.; Kooijman, H.; Spek, A. L.; Van Koten, G.; Gebbink, R.; Dalton Trans. 2010, 39, 6198.

8. Groves, J. T.; Nemo, T. E.; J. Am. Chem. Soc. 1983, 10, 5786.

9. Drain, C. M.; Smeureanu, G.; Patel, S.; Gong, X. C.; Garno, J. A.; New. J. Chem. 2006, 30, 1834.

10. Wang, Y. T.; Jin, W. J.; Spectrochim. Acta, Part A. 2008, 70, 871.

11. Komatsu, T.; Moritake, W.; Nakagawa, A.; Tsuchida, E.; Chem. --Eur. J. 2002, 8, 5469.

12. Nagami, H.; Umakoshi, H.; Shimanouchi, T.; Kuboi, R.; Biochem. Eng. J. 2004, 21, 221.
13. Szoka, F.; Papahadjopoulos, D.; Annu. Rev. Biophys. Bioeng. 1980, $9,467$.

14. Atkin, R.; Craig, V. S. J.; Wanless, E. J.; Biggs, S.; Adv. Colloid Interface Sci. 2003, 103, 219.

15. Grassert, I.; Schinkowski, K.; Vollhardt, D.; Oehme, G.; Chirality 1998, 10, 754.

16. Hait, S. K.; Moulik, S. P.; J. Surfactants Deterg. 2001, 4, 303.

17. Glick, J.; Santoyo, G.; Casey, P. J.; J. Biol. Chem. 1996, 271, 2949.

18. Maldotti, A.; Andreotti, L.; Molinari, A.; Varani, G.; Cerichelli, G.; Chiarini, M.; Green Chem. 2001, 3, 42.

19. Batrakova, E. V.; Kabanov, A. V.; J. Controlled Release 2008, 130, 98.

20. Bangham, A. D.; Standish, M. M.; Watkins, J. C.; J. Mol. Biol. 1965, 13, 238.

21. Johnson, S. M.; Bangham, A. D.; Hill, M.W.; Korn, E. D.; Biochim. Biophys. Acta, Biomembr. 1971, 233, 820.

22. Papahadj, D.; Watkins, J. C.; Biochim. Biophys. Acta, Biomembr. 1967, 135, 639.

23. Abramson, M. B.; Katzman, R.; Gregor, H. P.; J. Biol. Chem. 1964, 239, 70 .

24. Hauser, H. O.; Biochem. Biophys. Res. Commun. 1971, 45, 1049.

25. Huang, C. H.; Biochemistry 1969, 8, 344.

26. Saunders, L.; Gammack, D.; Perrin, J.; J. Pharm. Pharmacol. 1962, 14, 567.

27. Tien, H. T.; Bilayer Lipid Membranes (BLM): Theory and Practice, $1^{\text {th }}$ ed.; Marcel Dekker: New York, 1974.

28. Razin, S.; Biochim. Biophys. Acta, Biomembr. 1972, 265, 241.

29. Korenbrot, J. I.; Annu. Rev. Physiol. 1977, 39, 19.

30. Batzri, S.; Korn, E. D.; Biochim. Biophys. Acta, Biomembr. 1973, 298, 1015.

31. Deamer, D.; Bangham, A. D.; Biochim. Biophys. Acta, Biomembr. 1976, 443, 629.

32. Szoka, F.; Papahadjopoulos, D.; Proc. Natl. Acad. Sci. U. S. A. 1978, 75, 4194.

33. Mishra, P. P.; Bhatnagar, J.; Datta, A.; J. Phys. Chem. B. 2005, 109, 24225.

34. Pessoto, F. S.; Inada, N. M.; Nepomuceno, M. D.; Ruggiero, A. C.; Nascimento, O. R.; Vercesi, A. E.; Nantes, I. L.; Chem. Biol. Interact. 2009, 181, 400.

35. Steinbeck, C. A.; Hedin, N.; Chmelka, B. F.; Langmuir 2004, 20, 10399.

36. Vanesch, J. H.; Feiters, M. C.; Peters, A. M.; Nolte, R. J. M.; J. Phys. Chem. 1994, 98, 5541.

37. Barber, D. C.; Freitagbeeston, R. A.; Whitten, D. G.; J. Phys. Chem. 1991, 95, 4074.

38. Maiti, N. C.; Mazumdar, S.; Periasamy, N. J.; J. Porphyrins Phthalocyanines 1998, 2, 369.

39. Schmehl, R. H.; Whitten, D. G.; J. Phys. Chem. 1981, 85, 3473. 40. Perrin, M. H.; J. Chem. Phys. 1973, 59, 2090. 
41. Zhou, X. T.; Ji, H. B.; Chem. Eng. J. 2010, 156, 411.

42. Monnereau, C.; Ramos, P. H.; Deutman, A. B. C.; Elemans, J.; Nolte, R. J. M.; Rowan, A. E.; J. Am. Chem. Soc. 2010, 132, 1529.

43. Merlau, M. L.; Grande, W. J.; Nguyen, S. T.; Hupp, J. T.; J. Mol. Catal. A: Chem. 2000, 156, 79.

44. Anzenbacher, P.; Kral, V.; Jursikova, K.; Gunterova, J.; Kasal, A.; J. Mol. Catal. A: Chem. 1997, 118, 63.

45. Zhao, Y. C.; Xiang, Y. Z.; Pu, L.; Yang, M.; Yu, X. Q.; Appl. Catal., A 2006, 301, 176.

46. Zhou, X. T.; Tang, Q. H.; Ji, H. B.; Tetrahedron Lett. 2009, 50, 6601.

47. Monfared, H. H.; Aghapoor, V.; Ghorbanloo, M.; Mayer, P.; Appl. Catal., A 2010, 372, 209.

48. Heijnen, J. H. M.; de Bruijn, V. G.; Van Den Broeke, L. J. P.; Keurentjes, J. T. F.; Chem. Eng. Process. 2003, 42, 223.

49. Santos, A. C.; Luz, R. A. S.; Ferreira L. G. F.; Santos-Júnior, J. R.; Silva, W. C.; Quim. Nova, 2010, 33, 539.

50. Zhou, Y. B.; Ryu, E. H.; Zhao, Y.; Woo, L. K.; Organometallics 2007, 26, 358.

51. Nantes, I. L.; Crespilho, F. N.; Mugnol, K. C. U.; Chaves, J. C. A.; Luz, R. A. S.; Nascimento, O. R.; Pinto, S. M. S. In Circular Dichroism: Theory and Spectroscopy; Rodgers, D. S., ed.; Nova Science Publishers: New York, 2010, ch. 8.

52. Travascio, P.; Sen, D.; Bennet, A. J.; Can. J. Chem. 2006, 84, 613.

53. Omodeo-Sale, F.; Monti, D.; Olliaro, P.; Taramelli, D. P.; Biochem. Pharmacol. 2001, 61, 999.

54. Ishigure, S.; Mitsui, T.; Ito, S.; Kondo, Y.; Kawabe, S.; Kondo, M. Dewa, T.; Mino, H.; Itoh, S.; Nango, M.; Langmuir 2010, 26,7774

55. Umakoshi, H.; Morimoto, K.; Ohama, Y.; Nagami, H.; Shimanouchi, T.; Kuboi, R.; Langmuir 2008, 24, 4451.

56. Prieto, T.; Marcon, R. O.; Prado, F. M.; Caires, A. C. F.; Di Mascio, P.; Brochsztain, S.; Nascimento, O. R.; Nantes, I. L.; J. Phys.Chem. 2006, 8, 1963.

57. Mugnol, K. C. U.; Ando, R. A.; Nagayasu, R. Y.; Faljoni-Alario, A.; Brochsztain S.; Santos, P. S. Nascimento, O. R.; Nantes, I. L.; Biophys. J. 2008, 94, 4066.

58. Nagatomo, H.; Matsushita, Y.; Sugamoto, K.; Matsui, T.; Tetrahedron: Asymmetry 2003, 14, 2339.

59. Cantonetti, V.; Monti, D.; Venanzi, M.; Bombelli, C.; Ceccacci, F.; Mancini, G.; Tetrahedron: Asymmetry 2004, 15, 1969.

60. Hiraka, K.; Kanehisa, M.; Tamai, M.; Asayama, S.; Nagaoka, S.; Oyaizu, K.; Yuasa, M.; Kawakami, H.; Colloids Surf., B 2008, 67, 54.

61. Yuasa, M.; Oyaizu, K.; Horiuchi, A.; Ogata, A.; Hatsugai, T.; Yamaguchi, A.; Kawakami, H.; Mol. Pharm. 2004, 1, 387.

62. Aron, J.; Baldwin, D. A.; Marques, H. M.; Pratt, J. M.; Adams, P. A.; J. Inorg. Biochem. 1986, 27, 227.
63. Wang, J. S.; Vanwart, H. E.; J. Phys. Chem. 1989, 93, 7925.

64. Munro, O. Q.; Marques, H. M.; Inorg. Chem. 1996, 35, 3752.

65. Prieto, T,; Nascimento, O. R.; Tersariol, I. L. S.; Faljoni-Alario, A.; Nantes, I. L.; J. Phys. Chem. B 2004, 108, 11124.

66. Prieto, T.; Nantes, I. L.; Nascimento, O. R.; Prog. Colloid Polym. Sci. 2004, 128, 1.

67. Makarska, M.; Radzki, S.; Legendziewicz, J.; J. Alloys Compd. 2002, 341, 233.

68. Riposati, A.; Prieto, T.; Shida, C. S.; Nantes, I. L.; Nascimento, O. R.; J. Inorg. Biochem. 2006, 100, 226.

69. Claiborne, A.; Fridovich, I.; J. Biol. Chem. 1979, 254, 4245.

70. Hiner, A. N. P.; Ruiz, J. H.; Lopez, J. N. R.; Canovas, F. G.; Brisset, N. C.; Smith, A. T.; Arnao, M. B.; Acosta, M.; J. Biol. Chem. 2002, 277, 26879.

71. Primus, J. L.; Grunenwald, S.; Hagedoorn, P. L.; Albrecht-Gary, A. M.; Mandon, D.; Veeger, C. T.; J. Am. Chem. Soc. 2002, 124, 1214.

72. Demontellano, P. R. O.; Annu. Rev. Pharmacol. Toxicol. 1992, $32,89$.

73. Savenkova, M. I.; Kuo, J. M.; de Montellano, P. R. O.; Biochemistry 1998, 37, 10828.

74. Smith, A. T.; Veitch, N. C.; Curr. Opin. Chem. Biol. 1998, 2, 269.

75. Prieto, T.; Mugnol, K. C. U.; Araujo, J. C.; Sousa, F. L.; Soares,V. A.; Cilento, G.; Nantes, I. L. In Catalysis and Photochemistry in Heterogeneous Media; Nantes, I. L.; Brochesztain, S. eds.; Research Signpost: Kerala, 2007, ch. 1.

76. Zucchi, M. R.; Nascimento, O. R.; Faljoni-Alario, A.; Prieto, T.; Nantes, I. L.; Biochem. J. 2003, 370, 671.

77. Kinnunen, P. K. J.; Chem. Phys. Lipids 1992, 63, 251.

78. Kawai, C.; Prado, F. M.; Nunes, G. L. C.; Di Mascio, P.; Carmona-Ribeiro, A. M.; Nantes, I. L.; J. Biol. Chem. 2005, 280, 34709 .

79. Araujo, J. C.; Prieto, T.; Prado, F. M.; Trindade, F. J.; Nunes, G. L. C.; dos Santos, J. G.; Di Masco, P.; Castro, F. L.; Fernandes, G. J. T.; Valter, J. F.; Araujo, A. S.; Politi, M. J.; Brochsztain, S.; Nascimento, O. R.; Nantes, I. L.; J. Nanosci. Nanotechnol. 2007, 7, 3643.

80. Estevam, M. L.; Nascimento, O. R.; Baptista, M. S.; Di Mascio, P.; Prado, F. M.; Faljoni-Alario, A.; Zucchi, M. D.; Nantes, I. L.; J. Biol. Chem. 2004, 279, 39214.

81. Kawai, C.; Nantes, I. L.; Baptista, M. D. S.; FEBS J. 2010, 277, 224.

82. Nantes, I. L.; Faljoni-Alario, A.; Vercesi, A. E.; Santos, K. E.; Bechara, E. J. H.; Free Radic. Biol. Med. 1998, 25, 546.

Submitted: January 5, 2011 Published online: May 26, 2011

FAPESP has sponsored the publication of this article. 